УДК 801.3

DOI $10.17223 / 22274200 / 7 / 2$

\title{
Е.В. Иванцова
}

\section{ПРОЕКТ СОЗДАНИЯ ИДИОЛЕКТНОГО ТОПОНИМИЧЕСКОГО СЛОВАРЯ}

\begin{abstract}
Статья посвящена «Идиолектному словарю топонимов сибирского старожила», создаваемому в рамках проекта комплексного лексикографического представления феномена диалектной языковой личности. Рассматриваются место данного словаря в ряду близких по типу, его источники, состав, общая структура и структура словарных статей, даются их образиьы. Особенностями нового ономастикона являются опора на тексты устной речи конкретного диалектоносителя, максимально полное отражение всех разновидностей географических наименований, семантизация топонимов с позиций рядового говорящеего, отражение их функционирования через пометы и иллюстративные контекстиы.

Ключевые слова: топонимы, словарь, русские сибирские говоры, диалектная языковая личность.
\end{abstract}

Семейство топонимических словарей активно увеличивается в наши дни, отражая общую тенденцию внедрения лексикографического метода в практику одновременного представления и исследования языковых объектов $[1,2]$. Множатся разновидности словарных трудов. Среди них - ориентированные на отражение топонимической системы национального языка в целом и топонимии отдельных территорий; описание тех или иных классов топонимов (урбанонимов, гидронимов, ойконимов, микротопонимов конкретного города или села и т.д.). В рассматриваемой группе изданий имеют место словари нормативного и ненормативного типа, с этимологической, энциклопедической и лингвокультурной составляющей, алфавитные и алфавитно-гнездовые, одноязычные и двуязычные.

В связи с развитием лингвоперсонологического направления топонимия в последние десятилетия начинает находить отражение и в идиолектных словарях. Как правило, топонимы лексикографируются в составе ономастиконов, где представлены различные разряды имен собственных. Одним из первых изданий такого рода стал отдельный том «Словаря автобиографической трилогии М. Горького» [3]. Онимы включены в особые разделы «Частотного словаря романа Д.Н. Мамина-Сибиряка «Приваловские миллионы» [4], «Словаря 
языка русских произведений Шевченко» [5], «Словаря поэтического языка Марины Цветаевой» [6] и др. Е.Л. Гинзбургом разработаны теоретические основы построения «Словаря антропонимов» и «Словаря топонимов» в лексикографической серии «Словарь языка Достоевского», составлен словник имен персонажей писателя и топонимический словарь к роману «Бесы» [7. С. ХXXIII].

Как можно видеть, все эти словари отражают имена собственные в лексиконе известных писателей, элитарных языковых личностей. Источником так называемой авторской лексикографии (по Л.Л. Шестаковой) служат художественные тексты, дающие ценные сведения об идиолекте мастеров слова, но репрезентирующие только одну из форм речи - письменную. Словари языка писателей чаще дают общее представление об идиолектной онимии в целом, чем детальное описание ее отдельных классов. Обращает на себя внимание и тот факт, что до сих пор не создано ни одного ономастикона рядового носителя языка. На этом фоне «Идиолектный словарь топонимов сибирского старожила» (ИСТ), над которым в настоящее время ведется работа, заполняет некоторые лакуны в системе лексикографических трудов.

ИСТ является частью словарного комплекса, представляющего идиолект сибирского старожила Среднего Приобья. Задача максимально полной лексикографической презентации феномена диалектной языковой личности была поставлена в Томской диалектологической школе еще в 80-е гг. XX в. В настоящее время завершено издание базового 4-томного толкового словаря нарицательной лексики [8] и начато составление серии аспектных словарей, дополняющих его данные. В их число наряду с другими входит словарь топонимов носителя народно-речевой культуры.

Целью составления ИСТ является лексикографическая параметризация системы топонимов как важной составляющей ономастикона языковой личности и ее лексикона в целом. В словарной форме отражены топонимические номинации в идиолекте Веры Прокофьевны Вершининой, 1909 г. рожд., русской, малограмотной, коренной жительницы с. Вершинино Томской области.

Своеобразие типа создаваемого труда заключается в том, что он находится на пересечении классов ономастиконов, диалектных и идиолектных словарей, соединяя их черты. ИСТ - словарь регистрирующий, аспектный, отражающий результаты речевой деятельности 
рядового носителя языка, представителя традиционных русских народных говоров.

Основным источником ИСТ является корпус текстов живой разговорной речи диалектоносителя объемом около 10000 страниц. Материал собирался составителем словаря методом включения в языковое существование информанта в течение 24 лет (19812004 гг.). В качестве дополнительного источника сбора и интерпретации языкового материала привлекался «Полный словарь диалектной языковой личности». В отдельных случаях для уточнения официального статуса упоминаемых информантом объектов использовались также справочники по населенным пунктам среднеобского региона.

\section{Состав словаря}

Являясь составной частью серии словарей диалектной языковой личности, ИСТ вслед за базовым полным толковым словарем ориентирован на максимально широкое отражение единиц индивидуального лексикона.

Применительно к топонимам эта установка реализуется посредством включения в словник:

- разновидностей топонимов, относящихся ко всем видам номинируемых объектов: названиям государств и их отдельных регионов, областей и входящих в них районов; городов, деревень, поселков, а также частей, улиц, переулков и площадей этих населенных пунктов; морей, рек, проток, озер, болот, возвышенностей; участков сельскохозяйственного назначения;

- всех единиц идиолектной топонимической системы безотносительно к сфере их распространенности: официальных и неофициальных наименований географических объектов, известных и широкому кругу носителей русского языка, и территориально ограниченному коллективу представителей местного говора;

- топонимов, составляющих как ядерную, так и периферийную зоны идиолектной лексической системы. В ядро топонимии входят высокочастотные, свободно употребляемые языковой личностью онимы. К области периферии относятся главным образом неполно освоенные топонимы, воспроизведение звуковой оболочки которых вызывает у информанта затруднения: $A$ откэ'дова же они [конфетьл]? На букву «жээ». Жинто'мир ли кто там; В город приехали жить, а у их там сестра была в городе, на Каменной этой улице... 
Ка'мен... Ка'мен... Ка'менска ли как ли? В группу периферийных входят также немногочисленные новые и устаревающие топонимы и единичные лексемы, употребляющиеся только при цитировании чужих высказываний.

Кроме того, в ИСТ отражены производные от топонимов притяжательные прилагательные: московский, магадаевский, китайский и проч.

Исследование идиолексикона В.П. Вершининой показало, что в его составе не всегда возможно проведение жесткой границы между онимами и апеллятивами, с одной стороны, и онимами разных классов, с другой. Такой материал отражался в соответствии с общим принципом «мягкой» лексикографической подачи пограничных явлений лексикона диалектной языковой личности - через систему отсылочных статей к словарю нарицательной лексики и составляемому словарю антропонимов.

Не вошли в корпус словаря единицы, которые зафиксированы только в ситуации повтора за собеседником.

\section{Структура словаря}

Порядок расположения топонимов в словаре - алфавитный.

Формальные варианты топонимов - единицы, имеющие незначительные различия в звуковой оболочке при семантическом тождестве, - приводятся в одной словарной статье, также ранжируясь по алфавиту:

\section{ПА'РБИГ, ПА'РБИК, ПА'РБИКА}

При этом к вариантам, отличающимся начальным звуковым комплексом от первого звена вариантного ряда, даются отсылочные статьи:

\section{РУСАЛИМ СМ. ИРУСАЛИМ}

Топонимы, в состав которых входят служебные части речи, даются по типу фразеологизмов на знаменательный элемент:

\section{ИСТО'К • ЗА ИСТО'КОМ}

Омонимы (номинирующие разные объекты при совпадении звуковой оболочки) отражаются в отдельных словарных статьях с верхним цифровым индексом:

БАСАНДА'ЙКА' ${ }^{\mathbf{1}}$. Посёлок в окрестностях Томска.

БАСАНДА'ЙКА' $\mathbf{2}^{2}$. Деревня в Кемеровской области.

Притяжательные прилагательные даны в словарных статьях после соответствующих топонимов. Неоднословные номинации типа 
Ларинская елань, Ларинская гора даются при таких прилагательных как устойчивые словосочетания, в которых можно предположить еще не до конца завершенное развитие ономастической семантики:

ЛА'РИНСКИЙ. - Домов, наверно, семь тут-ка ларинских, привезёны с Ла'риной. Ларинская дорога. Ларинская гора. Ларинская eлань. - Два пая было: Ярска' ела'нь называлась... А тут от по Ларино... по Ларинской дороге. Дак она не Ларина, наша. Ларино... это... «На Ларинской» горе. На Ларинской, так звали; Там бере'зник был на Ела'ни на Ларинской ${ }^{1}$.

\section{Структура словарной статьи}

Словарная статья ИСТ включает следующие компоненты:

а) Заглавное слово в исходной словарной форме, с его формальными вариантами:

\section{АРМЕ'НИЯ}

КРАСНОЯ'РСК, КРАСНОЯ'РСКА

\section{ПО'ДБОР, ПО'Д БОРОМ}

Если в дискурсе В.П. Вершининой зафиксировано производное от топонима прилагательное, но не отмечен сам топоним, он приводился в заглавии словарной статьи со знаком реконструкции *:

\section{*МИНА'ЕВКА}

\section{МИНА'ЕВСКИЙ}

Апеллятив, обозначающий вид географического объекта, в заглавие словарной статьи в большинстве случаев не выносился: опускались слова улица, переулок, река, озеро, город. В то же время если топоним в речи диалектоносителя употребляется только в словосочетании с наименованием объекта (Иркутский тракт, Кузнечный взвоз, Набережная Ушайки, Приморский край, Кемеровская область, Чёрное море, Парме'ново озеро...), такие случаи в зоне заглавия подавались как целостные словосочетания.

б) При топонимах указываются диалектные формы словоизменения, зафиксированные в речи информанта:

БЕРЛИ'Н (р. Берли'на, Берли'ну).

ВАРЮ'ХИНА (р. и п. Варю'хиной, в. Варю'хину).

в) Спектр представленных в ИСТ функциональных помет достаточно узок, что связано с особенностями употребления данной

\footnotetext{
${ }^{1}$ Для иллюстрирования отдельных положений ИСТ словарные статьи приводятся в сокращенном виде или в виде фрагментов.
} 
группы онимов в дискурсивной практике диалектной языковой личности.

Для топонимов, не закрепленных в официальной номенклатуре городских и сельских населенных пунктов, давалась помета «неофициальное»:

ПСИХ, ПСИ'ХА. Неофии. Район Томска, где расположена психиатрическая больниия.

ПОЧТО'ВЫЙ, ПЯ'ТО ПОЧтО'ВЫЙ, ПЯ'ТЫЙ, ПЯ'ТЫЙ ПОЧТО'ВЫЙ. Неофиц. Закрытый город вблизи от Томска.

Помета о неполной освоенности топонима («неосвоенное») ставится, если в речи информанта наблюдается искажённое произношение имени собственного, маркеры неуверенности ли как ли, как кака' ли и под., скрытые проявления метаязыкового сознания (смех, усмешка) и др. Обычно эта помета используется в комбинации с пометой «окказиональное», указывающей на ситуативное порождение подобных образований в момент речи:

ФЕГУЛЬДЕ'Т, ФЕКУЛЬТЕ'Т. Неосв. Окказ. Деревня на севере Томской области. - [А первая семья у него в Томске?] Нет. Фегульдет ли Фекультет [смешок] ли там де-то, на севере.

ОПЕКЛЕ'НКО. Неосв. Окказ. Улица в Томске. - Опекленко, ли кака' ли улица... ну, та'мо-ка... ну, рядом с Южной тут живут де-то они. Они всё мне писали, адрес был, «ты заходи».

Пометы «новое» и «устаревающее» даются с учетом показаний метаязыкового сознания информанта, содержащих противопоставление «раньше / теперь»; на устаревание топонима могут также указывать сужение сферы его употребления до речевого жанра воспоминаний, преимущественное использование в контекстах глаголов речи в прошедшем времени (звали, называли и т.п.):

СЕ'ВЕРСК. Нов. Закрытый город вблизи от Томска, ранее неофициально называвшийся Почтовым или Пятым почтовым. - Потому что она не прописана в городе, на Пятом-то, в Северским теперь зовут. Она же в Томске прописана. А живёт там всё время.

САДО'ВАЯ. Устаревающ. Улища в Вершинино. - А там на улице, Садова улица была, звали, Победа счас зовут. [Там сады?] Ну, там сады, много было садов. А у нас тут не было нигде, ни у кого; А вот это Садова улица, где Катерина Васильевна жила, Садова была. Там много садов было, как сеча'с вот здесь. А у нас как-то мало тут было. 
К редким для топонимии функциональным пометам следует отнести «в чужой речи» (ЧР) и «в прецедентном тексте» (B прец.). Первая из них маркирует лексические единицы, зафиксированные в речи информанта только при цитировании чужих высказываний, вторая - онимы, отмеченные в составе общеизвестных в той или иной культуре текстов:

ЛИТВА'. ЧР. Одна из частей территории Советского Союза. Я говорю: «Володя, посмотри, каки' конфеты, чьи?» А он посмотрел: не по-нашему написано, всё, не по-русски. А он это: «Литва. Лито'вски».

ИРУСАЛИ'М, РУСАЛИ'М. $B$ прец. Город. - [Читает молитву:] Начина'тся молитва, сон Пресвятой Боүоро'дицы. Ма'ти Маре'я, де спала ночава'ла? В городе Ирусалиме, во по'льческой церькви, в алтаре на престоле; Дли'нна [молитва] - мама учила: «Начина'тся молитва, сон Пресвятой Боүородицы, ма'ти Мария, де спала ночавала? В городе Русалим, во по'льческой? церькви, в алтаре на престоле.

г) Особую проблему составляет в ИСТ представление зоны толкования географических номинаций.

В большинстве словарей топонимов даются сведения о мотивировке наименования, включая и их этимологию, и привязка лексикографируемых единиц к научной географической номенклатуре. Однако создание словаря диалектной языковой личности предполагает отражение семантики топонима с позиций рядового говорящего. Вопрос об актуальности исследования «фактического современного восприятия географического названия членами конкретного языкового коллектива, функционирования названия в сознании личности» [9. C. 7] уже ставится учеными с учетом развития современной антропоцентрической парадигмы науки. Особенно значим этот тезис для лингвоперсонологии, в том числе - лингвоперсонологических словарей, к которым относится и ИСТ.

Сложная задача отражения в словаре «наивной географии» диалектной языковой личности решалась с опорой на многолетнее включенное наблюдение над информантом с учетом его дискурсивной практики, словарного запаса и метатекстовых высказываний языковой личности. Исходя из этого принципа, в ИСТ не включались сведения об этимологии топонима, поскольку этимологические данные диалектоносителю неизвестны. 
Степень развернутости зоны толкования определялась характером представлений языковой личности о географическом объекте. При семантизации топонима могли находить отражение:

- вид географического объекта;

- его соотнесенность с другими объектами;

- мотивировочные признаки названия (в случае их осознания диалектоносителем);

- разнообразные периферийные представления носителя языка о статусе номинируемого объекта, его отличительных признаках, связанных с тем или иным наименованием событиях и т.д.

В связи с тем, что представления рядового говорящего в отношении отдельных объектов существенно различаются, толкование может быть как предельно обобщенным, так и максимально детализированным. Обязательным компонентом является только указание на вид географического объекта, прочие факультативны.

Указание вида объекта давалось исходя из объема лексикона рядового говорящего. В качестве основных единиц для наименования объектов используются государство (как политическая организация общества, занимающая определенную территорию), город, деревня, посёлок, район, улица, переулок, площадь, проспект, море, река, реч$\kappa a$, протока, болото, участок земли. Родовые наименования союзная республика, субъект Российской Федераџии, административнотерриториальная единица, регион и под. не употреблялись в словаpe, поскольку такие единицы в словарном запасе диалектоносителя не отмечены.

Несмотря на то, что ряд населенных пунктов среднеобского региона в справочниках назван сёлами, в ИСТ не производилось разграничение на сёла и деревни. Все крестьянские селения обозначены родовым компонентом деревня: лексема село низкочастотна в речи В.П. Вершининой; населенные пункты, официально носившие статус села (Вершинино, Варюхино, Коларово и др.), называются ею деревнями независимо от величины и наличия церкви; соотносится с этим пониманием и традиционная грамматическая форма женского рода (Верши'нина, Варю'хина, Кола'рова и под.).

Соотнесенность данного географического объекта с другими реконструировалась на основании дискурсивных данных.

При названиях государств соотнесение с единицами более высокого порядка (Европа/Азия, континент) не указывается в связи с от- 
сутствием таких знаний у диалектоносителя. Большинство топонимов этой группы являются семантически опустошенными:

АМЕ'РИКА. Государство.

ИРА'К. Государство.

При названиях городов степень конкретизации может быть различной - от общего указания на тип объекта до сведений о нахождении в той или иной стране или на какой-либо части ее территории:

СЕМИПАЛА'ТИНСК. Город.

УЛА'Н-УДЭ'. Город.

ЛЕНИНГРА'Д. Город в России.

УССУРИ'ЙСК. Город в России, на территории Приморского края.

Небольшие города Томской и Кемеровской областей обычно соотносятся информантом с официальными названиями областей:

ЮРГА'. Город в Кемеровской области.

А'СИНА. Город в Томской области.

Для внутригородских топонимов (как правило, находящихся в Томске) указывается вид урбанонима и город:

НИКИ'ТИНА. Улица в Томске.

РЕВОЛЮ'ЦИИ ПЛОЩАДЬ. Площадь в Томске.

КАШТА'К. Район Томска.

Сельские микротопонимы соотносятся с деревней, на территории которой расположены географические объекты, - как правило, с родным для информанта Вершининским поселением. При микротопонимах, обозначающих объекты внутри населенного пункта, конкретизация осуществляется через указание на вид объекта (часть села, улица), за его пределами - через указание на расположение земельных участков, отличающихся рельефом и сельскохозяйственным предназначением, по отношению к деревне:

ГОРЁВКА. Часть села Вериинино.

ПОБЕ'ДА' ${ }^{1}$. Улича в Вериинино.

ГРЯЗНУ'ШКИ. Участок земли в окрестностях Вершинино.

Сведения о существовании того или иного географического объекта или его статусе указывались на период сбора материала.

Специфика ряда топонимов в лексиконе В.П. Вершининой проявляется в одноименности обозначения той или иной территории улицы, неофициального названия района - и объекта, располагающегося на этой территории. Если контексты демонстрировали не- 
расчлененное употребление, подразумевающее одновременно и топоним, и топообъект, это отражается в зоне семантизации:

ДЕРЖИ'НКА, ДЗЕРЖИ'НКА. Район улищь Дзержинского с расположенным на ней базаром в Томске.

При наличии у рядового носителя языка иных устойчивых представлений, создающих образ географического объекта, они включаются в зону толкования в виде комментария:

БЕРЛИ'Н. Город, столица Германии. Взятие Берлина советскими войсками в 1945 г. осознается как окончательная победа России в Великой Отечественной войне.

ЧЕРНО'ПЫЛЬ. Город в Советском Союзе. Место крупной промышленной аварии.

ЧАЖЕМТО'. Деревня в Томской области. Место расположения одноименного санатория, известного минеральной водой и грязелечением.

В семантику наименований ликвидированных населенных пунктов входит также компонент «исчезнувший»:

СМОКОТНИНА'. Исчезнувшая деревня в Томской области.

Оттопонимические прилагательные с общим значением отношения даются в ИСТ при соответствующих топонимах без толкования:

КИТА'ЙСКИЙ. - Там всё вое'нны - де-то у китайской границы были, близко; То ли оно [мыло] китайско, то ли како'-то.

В качестве регулярного оттенка значения притяжательных прилагательных выделялся ЛСВ «живущий (живший) в том или ином населенном пункте»:

КАЛТА'ЙСКИЙ. Живущий (живший) в Калтае. - Пе'рва жена была калтайска у него [брата], с Калта'ю; А на ту-то сторону [реки] не перейдёшь, де калтайски. Те [жители] калтайски называются. Напро'ти Калта'й.

д) Справочные сведения.

В тех случаях, когда форма топонимов в лексиконе диалектоносителя отличается от официальной или имеет варианты, после зоны толкования со знаком < указывается официальное наименование:

БЕЛИ'НСКАЯ. Улица в Томске. < Белинского.



НОВОКУЗНЕ'ЦК, НОВОКУЗНЕ'ЦКА. Город в Кемеровской области. < Новокузнеик. 
Для ряда топонимов отмечено расхождение в родовом понятии: переулок может называться улицей, село - деревней, край - областью и т.п. Нормативная отнесенность также отмечается после знака $<$ : Ба'тенькова.

БАТЕНКО'ВА, БАТЕНКО'ВСКА. Улица в Томске. < пер.

Словарная статья содержит также сведения о числе зафиксированных в текстах словоупотреблений топонима.

е) Важное место в структуре словарной статьи занимает иллюстративная зона. Широкое включение контекстов должно дать пользователям Словаря представление о характере употребления топонимов в речи носителя традиционной народно-речевой культуры.

Согласно традициям томской диалектной лексикографии иллюстративный материал словаря отражает черты диалектного произношения в упрощённой орфографической форме. Реплики собирателей и пояснения составителя словаря даются в квадратных скобках, реплики диалектоносителей в диалоге маркируются инициалами говорящих. Фрагменты связного текста отделяются друг от друга точкой с запятой.

Количество приводимых примеров определялось частотностью топонима в дискурсе В.П. Вершининой, а также зависело от разнообразия встречающихся случаев его функционирования. При наличии большого числа примеров отражались валентностные связи онима, приводились фрагменты как монологической речи информанта, так и диалогов с односельчанами. Основной массив контекстов репрезентирует спонтанную речь диалектной языковой личности; его дополняют отмеченные знаком показания метаязыкового сознания, отражающие рефлексию говорящего относительно наличия местного топонима, мотивов называния, замены одного обозначения другим и т.д.

Приведем образцы словарных статей ИСТ.

БАТУ'РИНА (в. Бату'рину, р., т. и п. Бату'риной), БАТУ'РИНО. Деревня вблизи от Вершинино. < с. Батурино. 64/12. - Ходили раньше по' миру. О-ой, из Батуриной приезжали, ходили по' миру здесь; Много ши'бко [план страховки]. Я говорю: «Тебе надо в Батурину, в Батурину нихто' не идёт»; И из Батуриной были 
народ, из Верши'ниной, с Я'ру были, с Ярско'го [на празднике]; А ругаться станут - ой! Будут там ругаться - дак наверно, в Батуриной слыхать; Она гыт: «Заедемте ко Клавке?» Я говорю: «Нет, не поедем». Поехали домой. [Это кто?] В Батурино. Хотела ко Клавке заехать там-ка; А одна старуха в Батурино умерла, а втора' старуха мне говорила.

БАТУ'РИНСКИЙ, БАТУ'РСКИЙ. Живущзий (живший) в Батурино. 3/43. - А как она уехала, а батуринский мужик приходит ко мне, он в Батуриной живёт; Ну она была кандидат. Проголосовали Яр и батурински за неё, гыт; А я думаю: и так негде, столько народу у них, и чужого - батурски были, я'рски были, вся'ки, я говорю, и он там ночава'ть вздумал; Как эта батурска баба накупила обнов-то; Ну, Света, от это, от батурского-то [дочь], помнишь?

ВОСТО'К. Территория на востоке России. < Дальний Восток. 6. - Андрюша в армии служит. Ага. Где-то он далёко. Ага, на Востоке де-то, я забыла. На Востоке; Ню'ре, моёй сестры мну'ка, Витьку. Взяли, гыт, на Восток; Ф.Г. Ты де, Коля, служил? Н.Н. На севере Урала. «У Печоры у реки». В.П. А Володя на Востоке, однако. А Юра тоже на Востоке; В.П. Она [родственница]: «Я бы пропуск тебе выхлопотала, всё бы, гыт, это...» М.А. Это кто звал, Шура? В.П. Шура. На Востоке тоже.

ЗАГО'РСКА. Город в Подмосковье. < Загорск. 2. - А у меня там знако'ма, она... даже сродни' мне. Из этого вот дому. Катя. Она маало жила тоже! А это... в деревне. Всё в городе жила. А работала она на заводе. О'споди... в Подмосковье, какой там ешо город-то? Де-то... Загорска. В Загорска их отправили.

ИРА'К. Государство. 1. - Ну, это где-то, гыт... как война начиналась где-то та'мо-ка... в Ираке ли где ли. Там война начиналась, они, гыт, по'мочь от войны. А война перестала там. Они разослали вот по таким. Ну, всем почти давали, многим давали [гуманитарную помощь].

ИСТО'К • ЗА ИСТО'КОМ. Неофий. Старый район Томска вблизи реки. 3. - Дак он каку'-то закалку изде'лал гаражу, - машину купил, гараж купил, всё изде'лал, а гараж За Истоком; В городе они живут. Я не знаю, де они живут. А гараж у их за этой... ну, там...За Истоком де-то; [У нас кондитерский За Истоком]. За Истоком? Там Шура-то эта моя, на Татарской живёт, недалёко туды'. 
КО'БЫСОВА • НА КО'БЫСОВОЙ. Земельный участок в окрестностях Вершинино. 4. - Это назывался По'дбор, теперь на Ни'жном - это уж чё, сколько полей... Кузнецово, на Кобысовой... Покосы были. Сеяли и покосы были.

КОНЁВА (в. Конёву, П. Конёвой), КОНЁВО. Исчезнувшая деревня в Томской области. 2/1. - А дак... мы купили эту избушонкуто. Мы купили дом, хоро-оший, в Конёвой, а потом это...; А он купил, где Николай Васильичев дом-то, Степан съездил в Конёво, купил, там продавали дома'; Степан съездил, в эту, в Конёву, купил там дом.

ЛЕНИНГРА'Д. Город в России. 1. - А у ей сын де-то далёко, в Ленинграде ли где ли, Юрка, а дочка-то тут-ка, в Томске.

ЛЕНИНГРА'ДСКИЙ. Живущзй (живщий) в Ленинграде. 2. Ленинградских пустила на кварте'ру [в войну]; У меня ленинградски жили, ба'ушка там одна, оттэ'дова, секлета'рь сельсовета, она устроилась ко мне...

ПАНЬКО'ВА. Протока реки Томи около деревни Калтай. 3. Томь одна, а там-ка Панькова - рукав такой, протока, Паньковой лёд прошёл, по Светлой.

СИБИ'РЬ. Обширная часть территории России с холодным климатом. 2. - [А ссыльные здесь жили?] Помню, конешно, австрийцы каки'-то были здесь. А так я не знаю ши'бко никого. Ну, говорили, что в Сибирь ссылали; Шура, Марусина сестра, дак она: «Ой, в Сибири только пельмени и делают».

ТАТА'РЫ. Устареваюш. Часть деревни Вершинино, где когдато жили татары. 4. - ^ Улицу... там тот край всё звали «Татары». «В Татары пойдёмте»; А на горке уж Горка, Горкой называли. Ну вот где Физа живёт, туды' подальше так мале'нько. А там Татары. [А почему «Татары»?] А там татары жили, там в краю, наверно, из-за то. Давно кода'-то татары жили.

ЧЕБОКСА'РЫ. Нов. Одна из новых частей деревни Вершинино. 1. - «Чебоксары» там зовут, там сколько настроили домов, сколько живут, и там, в тем краю - много.

В «Идиолектный словарь топонимов сибирского старожила» вошло около 300 словарных статей (без учета притяжательных прилагательных). Он дает исследователю широкий круг сведений о топонимической составляющей лексикона диалектоносителя, ее коли- 
чественных, качественных и функциональных характеристиках. Материалы словаря будут полезны диалектологам, ономатологам, лингвокультурологам, занимающимся проблемами семантики имен собственных, метаязыковой рефлексии в сфере ономастики, реконструкции представлений носителя языка о пространственной организации мира. Данный источник, думается, может внести свою лепту как в изучение диалектной языковой личности, так и - шире - рядового носителя языка вообще.

\section{Лuтература}

1. Блинова О.И. Лексикографический метод исследования языка // Природные и интеллектуальные ресурсы Сибири (СИБРЕСУРС-3-97): 3-я Междунар. науч.-практ. конф., 13-15 октября 1997 г. - Томск, 1997. - С. 148-149.

2. Гавар М.Э. Лексикографический метод и его применение в исследовании диалектной синонимии // Вестн. Том. гос. ун-та. - 2014. - № 384. - С. 11-17.

3. Словарь автобиографической трилогии М. Горького. Имена собственные (личные имена, географические названия и заглавия литературных произведений) / сост. А.В. Федоров, О.И. Фонякова. - Л.: Изд-во ЛГУ, 1975.

4. Генкель М.Г. Частотный словарь романа М.Н. Мамина-Сибиряка «Приваловские миллионы». - М.: Наука, 1987.

5. Словарь языка русских произведений Шевченко: в 2 т. - Т. 2. - Киев: Наукова думка, 1986.

6. Словарь собственных имен и названий // Словарь поэтического языка Марины Цветаевой: в 4 т. Т. 4, кн. 2 / сост. И.Ю. Белякова, И.П. Оловянникова, О.Г. Ревзина. - М., 2004. - С. 627-730.

7. Караулов Ю.Н., Гинзбург Е.Л. Язык и мысль Достоевского в словарном отображении // Словарь языка Достоевского: Лексический строй идиолекта. Вып. 1 / гл. ред. Ю.Н. Караулов. - М., 2001. - С. IX-LXIV.

8. Полный словарь диалектной языковой личности / под ред. Е.В. Иванцовой. Томск: Изд-во Том. ун-та, 2006-2012. - Т. 1-4.

9. Голев Н.Д., Дмитрева Л.М. Единство онтологического и ментального бытия топонимической системы (к проблематике когнитивной топонимики) // Вопросы ономастики. - 2008. - № 5. - С. 5-17.

\section{THE PROJECT OF AN IDIOLECT TOPONYMIC DICTIONARY.}

Journal of Lexicography, 2015, 1(7), pp. 20-35. DOI 10.17223/22274200/7/2

Ivantsova Yekaterina V., Tomsk State University (Tomsk, Russian Federation).

E-mail: ekivancova@yandex.ru

Keywords: toponyms, dictionary, Russian Siberian dialects, dialectal language personality.

The review of existing toponymic dictionaries shows the diversity of their objectives and principles, including the increasing interest in idiolect onomasticons. However, the linguopersonology trend in proper name lexicography today is represented only in writer's language dictionaries and based on the data of the authors' written speech. The new 
Idiolect Dictionary of Toponyms of the Siberian Old-Timer has some significant differences from them. It is at the intersection of onomasticons, dialect and idiolect dictionaries, combining their features. Typologically, the Dictionary is registering, aspect, first reflecting the specific geographic nominations of an ordinary individual. It is part of the dictionary complex which presents the idiolect of a Siberian Middle Ob Old-Timer, V.P. Vershinina, born in 1909.

The main source of the dictionary was texts of live colloquial speech of the dialect speaker of about 10,000 pages in volume. In forming the glossary, after the initial full explanatory dictionary of nominal vocabulary, the aim was to most broadly reflect the individual units of the lexicon which includes all kinds of toponyms relating to different kinds of geographical objects, official and unofficial names of the nuclear and peripheral zones of onyms and possessive adjectives derived from toponyms.

The article describes the general structure of the Dictionary and the structure of its entries which include the head word in its basic dictionary form with its formal options; dialectal features of inflection; marks ("informal", "undeveloped", "occasional", "new", "obsolescent", "in alien speech", "in the precedent text"); interpretation of the meaning; reference information; illustrative material. In semantization of toponyms an attempt is made to reflect the ideas of geographic objects from the standpoint of an ordinary speaker. In this connection, interpretation can be both very generalized (specifying the form of the object only) and most detailed. The reference zone indicates the number of recorded uses of the toponym and, if necessary, its official name. Contexts represent spontaneous speech of the dialectal language personality and metalinguistic consciousness representations, the object of which is toponyms. Samples of entries are given.

The Idiolect Dictionary of Toponyms of the Siberian Old-Timer includes about 300 entries. It gives the researcher a wide range of information on the toponymic part of the dialect speaker's lexicon, its quantitative, qualitative and functional characteristics. The dictionary materials will be useful for experts in dialectology, onomastics, cultural linguistics who deal with the problems of semantics of proper names, metalinguistic reflection in the field of onomastics, reconstruction of a native speaker's representations of the spatial organization of the world. This source can make a contribution to the study of the dialect language personality and, broader, the average native speaker in general.

\section{References}

1. Blinova, O.I. (1997) [Lexicographic method of the language study]. Prirodnye $i$ intellektual'nye resursy Sibiri (SIBRESURS-3-97) [Natural and intellectual resources of Siberia (SIBRESURS-3-97)]. Proc. of the Third International Scientific and Practical Conference. 13th to 15th October 1997. Tomsk. pp. 148-149. (In Russian).

2. Gavar, M.E. (2014) Lexicographic method and its application in the research of dialect synonymy. Vestnik Tomskogo gosudarstvennogo universiteta - Tomsk State University Journal. 384. pp. 11-17. (In Russian).

3. Fedorov, A.V. \& Fonyakova, O.I. (1975) Slovar' avtobiograficheskoy trilogii M. Gor'kogo. Imena sobstvennye (lichnye imena, geograficheskie nazvaniya i zaglaviya literaturnykh proizvedeniy) [Glossary of Gorky's autobiographical trilogy. Proper names (personal names, geographical names and titles of fiction)]. Leningrad: Leningrad State University. 
4. Genkel', M.G. (1987) Chastotnyy slovar' romana D.N. Mamina-Sibiryaka 'Privalovskie milliony" [The Frequency Dictionary of D.N. Mamin-Sibiryak's novel "Privalov's Millions"]. Moscow: Nauka.

5. Beloded, I.K. (ed.) (1986) Slovar' yazyka russkikh proizvedeniy Shevchenko [The Dictionary of the Russian Works by Shevchenko]. V. 2. Kiev: Naukova dumka.

6. Belyakova, I.Yu., Olovyannikova, I.P. \& Revzina, O.G. (2004) Slovar' sobstvennykh imen i nazvaniy [The Dictionary of Proper Names and Titles]. In: Belyakova, I.Yu., Olovyannikova, I.P. \& Revzina, O.G. Slovar' poeticheskogo yazyka Mariny Tsvetaevoy [The Dictionary of the Poetic Language of Marina Tsvetaeva]. V. 4. Book 2. Moscow: Dom-muzey Mariny Tsvetaevoy.

7. Karaulov, Yu.N. \& Ginzburg, E.L. (2001) Yazyk i mysl' Dostoevskogo v slovarnom otobrazhenii [Language and thought of Dostoevsky as reflected in the dictionary]. In: Karaulov, Yu.N. (ed.) Slovar' yazyka Dostoevskogo. Leksicheskiy stroy idiolekta [The Dictionary of Dostoevsky's Language. The Lexical System of the Idiolect]. Is. 1. Moscow: Azbukovnik.

8. Ivantsova, Ye.V. (ed.) (2006-2012) Polnyy slovar' dialektnoy yazykovoy lichnosti [The Complete Dictionary of the Dialect Language Personality]. V. 1-4.Tomsk: Tomsk State University.

9. Golev, N.D. \& Dmitreva, L.M. (2008) Unity of the Ontological and Mental Existence of the Toponymic System: A Contribution to Cognitive Toponymics. Voprosy onomastiki-Problems of Onomastics. 5. pp. 5-17. (In Russian). 